\title{
Effect of Non genetic Factors on Weight Traits of Local Tarai Goats under Farmers' Managed Condition
}

\author{
Nirajan Bhattarai ${ }^{1}$ and Saroj Sapkota ${ }^{2}$ \\ ${ }^{1}$ Institute of Agriculture and Animal Science (IAAS), Rampur, Chitwan \\ ${ }^{2}$ Innovative Energy and Environment Nepal (IEEN), Kathmandu
}

\begin{abstract}
A field study was carried out to characterize, evaluate and estimate the effect of non-genetic factors on the productive and reproductive performance of local Terai goats during March 2006 to February 2007 in Siraha, district. Altogether 206 dams and 318 kids of different age groups were identified for this study and data on productive performance was collected based on periodic field monitoring. The mean body weight of kids at birth, pre-weaning, weaning, and post weaning at 6 and at 8 months were was $2.23 \pm 0.04,5.75 \pm 0.16,10.18 \pm 0.23,13.67 \pm 0.28$, and $19.31 \pm 0.44 \mathrm{~kg}$, respectively. Among the non-genetic factors, parity significantly $(\mathrm{p}<0.05)$ influenced but only to post-weaning weight of kids at 8 months. Post weaning weight of kids at 6 and 8 months significantly differed $(\mathrm{p}<0.05)$ with respect to sex, and birth type significantly differed to the body weight at birth $(\mathrm{p}<0.001)$, pre-weaning $(\mathrm{p}<0.01)$, weaning and at 6 months post-weaning $(\mathrm{p}<0.05)$ age. Thus, the results of this study suggested that the overall productivity of local Terai goat breed could be improved through selective breeding practices, especially by considering the non genetic factors such as, birth type and sex of kids.
\end{abstract}

Key words: birth type, sex, weight, parity, weaning

\section{Introduction}

The major livestock species preferred in Nepal are usually cattle, buffaloes, goats, sheep and pigs with a population of 7.2 million, 4.8 million 8.8 million 0.8 million, and $1.06 \mathrm{mln}$ respectively (MOAC 2009/10). Easy care, less feed requirement and disease resistance are the reasons for making goats very popular, and its distribution in all ecological regions, ranging from coldarid to hot-humid (Acharya 1992). MOAC, 2009/10 shows 8.84 millions goats available in Nepal with an annual average growth rate of 3.34 percent. Goat meat alone shares about 20 percent of total meat production of 250,213 mt (MOAC 2009/10).
Four commonly recognized indigenous goat breeds are found in Nepal namely: Chyangra, Sinhal, Khari and Terai corresponding to each ecological zone from north to south (Pradhan \& Gurung 1985, Kharel 1997) locating in Mountains, High hills, Mid-hills and Terai region of Nepal respectively. Goats found in different ecological belts are morphologically different. Moreover, goats found in central Terai region of Nepal appeared to be different from recognized Terai goats in term of productive and reproductive performance. They have comparatively larger body size, higher live body weight, and twinning ability (Neopane 2000). 
However, there are insufficient scientific evidences to characterize their productive and reproductive performance.

The major constraints for improvement of the indigenous goat breeds are due to its scattered population, lack of performance records and lack of selection plan (Neopane, 1998). Poor management and uncontrolled mating systems are also the important problems of goat farming in Nepal. Large number of flocks is being deteriorated due to inbreeding because farmers are using the same breeding buck for several years to their flock.

There is little information on characterization of indigenous Terai goats based on the morphological measurements; most of the characteristics are yet to be standardized. Therefore they need to be identified and conserved for future generation. This study was designed to characterize and evaluate the Terai goats located in Siraha district of Eastern Development Nepal that will assist for improving the genetic potentiality and overall productivity of these goats in future to come.

\section{Methodology}

This study was carried out between March, 2006 to February, 2007 in Siraha district of Eastern Development Region of Nepal. Dhodna and Bandipur VDCs of the district were purposively selected for the study. The experimental sites were identified as goat production pocket by the District Livestock Service Office (DLSO), Siraha. The entire population of goat kids available in the research site (VDCs) during the study period classified into different groups on the basis of their age. The age groups were birth, preweaning ( 2 month), weaning ( 4 month), post-weaning $1^{\text {st }}$ (6 months) and post-weaning $2^{\text {nd }}$ ( 8 months), and morphological measurements were recorded based on those groups. Altogether 206 dams and 318 kids were sampled with the observational distribution of 187 at birth, 165 at pre-weaning, 170 at weaning, 156 at $1^{\text {st }}$ post-weaning, and 64 at $2^{\text {nd }}$ post-weaning.

Growth performance of the goat kids was measured in term of their live body weight and recorded by using a dial scale balance fixed at a point above the ground. Body weight traits of the kids at different stages of growth were measured on monthly interval for 10 months. The non-genetic factors (fixed effects) that were related to the growth performance were dams' parity, sex and birth type of kids, whereas, non-genetic factors related to the litter traits and reproductive traits of Terai goats were the season of birth and dam's parity. For knowing the main causes of variation and effects of non genetic factors on productive and reproductive traits, as well as for overcoming the difficulty of disproportionate subclass numbers, data were analyzed by least squares procedure using Harvey (1990) software package. Statistically significant means were compared using the Duncan's multiple range test (DMRT) computer package. A fixed effect model given by Henderson (1953) was also used to analyze the body weight of kids at different stages of growth.

\section{Results and Discussion}

The overall least square mean and standard error of means for body weight at birth, pre-weaning, weaning, first post weaning and second post weaning of Terai goat kids were observed as $2.23 \pm 0.04 \mathrm{~kg}, 5.75 \pm 0.16$ $\mathrm{kg}, 10.18 \pm 0.23 \mathrm{~kg}, 13.67 \pm 0.28 \mathrm{~kg}$, and $19.31 \pm 0.44 \mathrm{~kg}$ respectively. Increment pattern of all the morphological traits of kids was similar at all growth stages of the kids. Higher values of all those traits at each stage of growth was observed for males compared to the female kids. The non-genetic factors such as dams' parity, sex, and birth type of kids revealed that birth weight, pre-weaning weight, weaning weight, and 6 months post weaning weight significantly differed with respect to the parity of dams, whereas, 8 months post-weaning weight of kids was significantly $(\mathrm{p}<0.05)$ differed with parity. Body weight at birth, pre-weaning and weaning also differed non- significantly with respect to sex of kids, whereas, their 8 months post weaning weight of kids significantly $(\mathrm{p}<0.05)$ differed by sex. Likewise, there were significant differences in birth type for body weight at birth $(\mathrm{p}<0.001)$, pre-weaning $(\mathrm{p}<0.01)$, weaning and 6 months post-weaning $(\mathrm{p}<0.05)$, except at 8 months post weaning age of Terai goat kids.

There is wider scope of enhancing the overall productivity of local Terai goat breed by considering the non genetic factors such as birth type with respect to the weight traits of kids, and reproductive performance of the does such as gestation length, kidding interval, post partum estrus, litter size, and litter weight. The sex of kids as revealed from this study 
Nirajan Bhattarai \& Saroj Sapkota/Effect of Non Genetic........

Table 1. Effect of dams' parity, sex and birth type of kids on birth, pre-weaning, weaning and post weaning Terai goat kids reared under farmers' condition at Siraha district, 2006/07

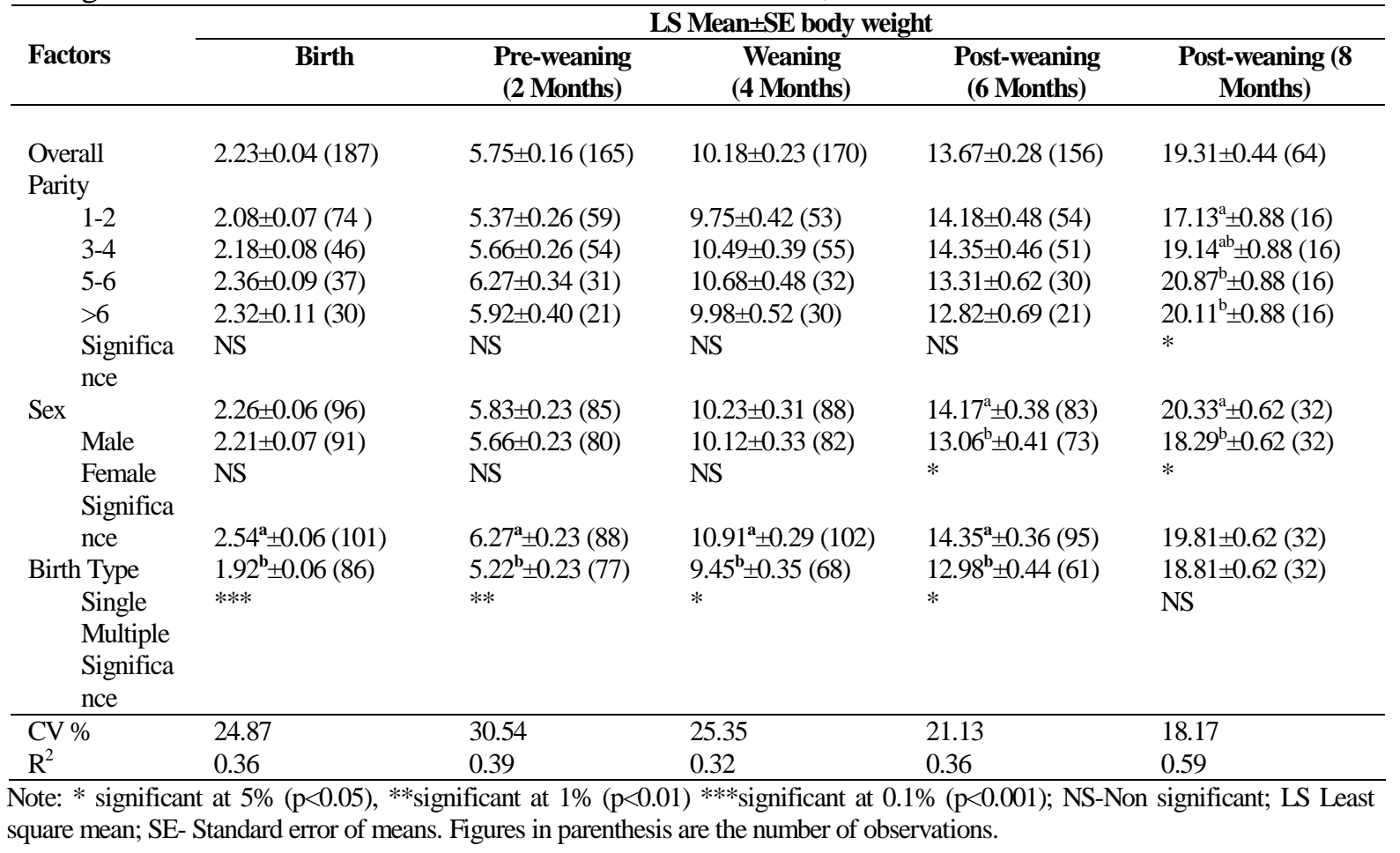

has significant influence on the body weight of the kids at later age which can be as an important factor for improving the productive performance of these goats in term of improvement in meat production.

\section{Acknowledgements}

We feel immense pleasure in expressing our deep sense of gratitude, appreciation and indebtedness to Professor Dr. Mohan Prasad Sharma, Professor Dr. Mana Raj Kolachhapati, Department of Animal Breeding and Biotechnology, and Professor Dr. Naba Raj Devkota, Department of Animal Nutrition and Fodder Production, Institute of Agriculture and Animal Science, Rampur, Chitwan for their constant guidance, constructive criticism, continuous encouragement, persistent inspiration and supervision throughout the course of this study. Thanks also extend to the farmers of Siraha district.

\section{References}

Acharya, R.M. 1992. Recent advances in goat production. In: Proceedings of papers presented at $5^{\text {th }}$ National Conference on Goats ( March 2-8, 1992), New Delhi (Ed. R.R. Lokeshwar ). pp. 49-93.
Harvey, W.R. 1990. Users' guide for LSMLMW and MIXMDL. PC-2 Version. Mixed Model. Least squares and Maximum Livelihood Computer Program.

Henderson, C.R. 1953. Estimation of variance and covariance components. Biometrics 9: 226-252.

MOAC. 20/10. Selected indicators of Nepalese agriculture and population. Agri-business Promotion and Statistics Division (ABPSD). Ministry of Agriculture and Cooperatives Singh Durbar, Kathmandu, Nepal.

Kharel, M. 1997. Goat (Capra hircus) genetic resources in Nepal. Veterinary review 12(1): 14-16.

Neopane, S.P. 1998. Genetic potential of hill goats: conservation through improvement. In: Proceedings of Fourth global conference on conservation of domestic animal genetic resources (August 17-21, 1998), Lalitpur (Ed. J.N.B Shrestha). Nepal Agriculture Research Council (NARC), Khumaltar, pp. 27-29.

Neopane, S.P. 2000. Characterization of local breed of goat in central terai of Nepal. In: Proceedings of fourth National Workshop on Livestock and Fisheries Research in Nepal (April 24-26, 2000), Lalitpur (Ed. T.B. Gurung). National Animal Science Research Institute (NASRI)/ NARC, Khumaltar, pp. 214-217.

Pradhan, S.L., and N.K. Gurung. 1985. Comparative performance of Khari (local hill goat) and its crossbred with Jamunapari of central goat farm, Bandipur. Nepalese Journal of Animal Sciences 1(1):35-40. 
Nepal Journal of Science and Technology 12 (2011) 51-54 